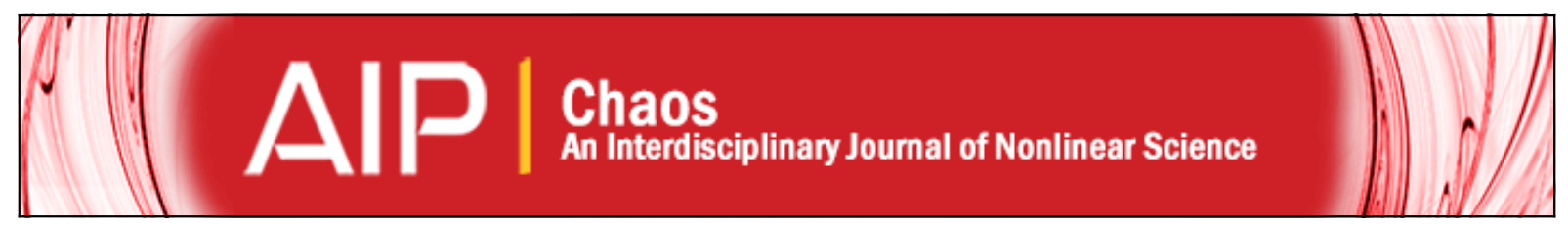

\title{
Mathematical model of the cell division cycle of fission yeast
}

Bela Novak, Zsuzsa Pataki, Andrea Ciliberto, and John J. Tyson

Citation: Chaos: An Interdisciplinary Journal of Nonlinear Science 11, 277 (2001); doi: 10.1063/1.1345725

View online: http://dx.doi.org/10.1063/1.1345725

View Table of Contents: http://scitation.aip.org/content/aip/journal/chaos/11/1?ver=pdfcov

Published by the AIP Publishing

\section{AlP Re-register for Table of Content Alerts}




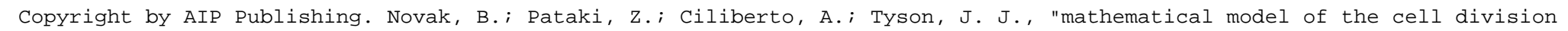
cycle of fission yeast," Chaos 11, 277 (2001); http://dx.doi.org/10.1063/1.1345725

\title{
Mathematical model of the cell division cycle of fission yeast
}

\author{
Bela Novak ${ }^{\mathrm{a})}$ and Zsuzsa Pataki \\ Department of Agricultural Chemical Technology, Budapest University of Technology and Economics, \\ Szt Gellert ter 4, 1111 Budapest, Hungary \\ Andrea Ciliberto and John J. Tyson ${ }^{\text {b) }}$ \\ Department of Biology, Virginia Polytechnic Institute and State University, Blacksburg, Virginia 24061
}

(Received 25 October 2000; accepted for publication 7 December 2000)

\begin{abstract}
Much is known about the genes and proteins controlling the cell cycle of fission yeast. Can these molecular components be spun together into a consistent mechanism that accounts for the observed behavior of growth and division in fission yeast cells? To answer this question, we propose a mechanism for the control system, convert it into a set of 14 differential and algebraic equations, study these equations by numerical simulation and bifurcation theory, and compare our results to the physiology of wild-type and mutant cells. In wild-type cells, progress through the cell cycle $(\mathrm{G} 1 \rightarrow \mathrm{S} \rightarrow \mathrm{G} 2 \rightarrow \mathrm{M})$ is related to cyclic progression around a hysteresis loop, driven by cell growth and chromosome alignment on the metaphase plate. However, the control system operates much differently in double-mutant cells, wee $1^{-} c d c 25 \Delta$, which are defective in progress through the latter half of the cell cycle (G2 and M phases). These cells exhibit "quantized" cycles (interdivision times clustering around 90, 160, and $230 \mathrm{~min}$ ). We show that these quantized cycles are associated with a supercritical Hopf bifurcation in the mechanism, when the wee 1 and $c d c 25$ genes are disabled. (C) 2001 American Institute of Physics. [DOI: 10.1063/1.1345725]
\end{abstract}

To reproduce itself, a cell must replicate all of its components and divide into two nearly identical daughter cells. During this cycle, the cell's deoxyribonucleic acid (DNA), which stores its genetic information, must be replicated precisely, and the two copies of each DNA molecule (called sister chromatids) must be segregated accurately to the daughter cells (Fig. 1). In eukaryotic cells, these two steps, called DNA replication and mitosis, occur during distinct temporal phases of the cell cycle ( $S$ phase and M phase) separated by gaps (G1 and G2). Maintaining the correct order of events is the responsibility of the cell cycle engine. ${ }^{1}$ Over the past 20 years, molecular biologists have uncovered many components of this engine. Cellcycle genes from one species can often replace their counterparts in other species, even between yeast and human cells, indicating that the cell cycle engine is an ancient and highly conserved mechanism among eukaryotes. From such discoveries, we can now construct schematic diagrams of the cell cycle engine in many different species, ${ }^{2,3}$ but how can we be sure that a diagram is consistent with the overall physiology of cell division in any particular species? Biochemical reaction kinetics, in combination with the modern theory of nonlinear dynamical systems, provide just the tool we need to derive the physiological consequences of complex molecular regulatory networks. We illustrate this tool by associating some unusual features of the fission yeast cell cycle to bifurcations in the system of equations describing its cell cycle engine.

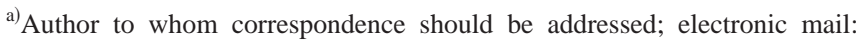
bnovak@chem.bme.hu

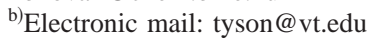

\section{INTRODUCTION}

\section{A. Molecular components of the cell cycle engine}

The most important components of the eukaryotic cell cycle engine are cyclin-dependent protein kinases, heterodimers consisting of a catalytic subunit (a Cdk) and a regulatory subunit (a cyclin). Cdks, which are active only in complex with a cyclin partner, exert their action by phosphorylating other proteins. ${ }^{1}$ Their protein-kinase activity is required to start both DNA replication and mitosis. Lower eukaryotes use only one essential Cdk subunit (generally called Cdk1), while higher eukaryotes use many. Cdk1 is often called $\mathrm{Cdc} 2$, in recognition of the gene $(c d c 2)$ that encodes this protein in fission yeast. ${ }^{4}$

In fission yeast, a unicellular eukaryote, complexes between Cdk1 and B-type cyclins play the major roles in cell cycle regulation. ${ }^{5} \mathrm{Cdc} 13$ is the only essential B-type cyclin. ${ }^{5}$ Deletion of the gene encoding $\mathrm{Cdc13}(c d c 13 \Delta)$ produces mutant cells that cannot enter mitosis. ${ }^{6}$ Two other B-type cyclins, Cig1 and Cig2, are normally involved in DNA synthesis, but in their absence, the $\mathrm{Cdc} 2 / \mathrm{Cdc} 13$ complex can drive the cell through $\mathrm{S}$ phase and $\mathrm{M}$ phase. ${ }^{7}$ During cell cycles driven by $\mathrm{Cdc} 2 / \mathrm{Cdc} 13$ alone, $\mathrm{S}$ phase always precedes mitosis, suggesting that the kinase requirement for $\mathrm{S}$ phase is lower than for M phase. ${ }^{8}$

DNA replication occurs once per cycle because Cdk activity not only triggers DNA replication but also inhibits rereplication of DNA. ${ }^{8}$ To start DNA synthesis, Cdk activity causes properly licensed origins of replication to begin copying the chromosome, and at the same time it phosphorylates licensing factor molecules, making them more susceptible to degradation. Disappearance of licensing factors from the nucleus prevents further rounds of replication. Cdk activity 


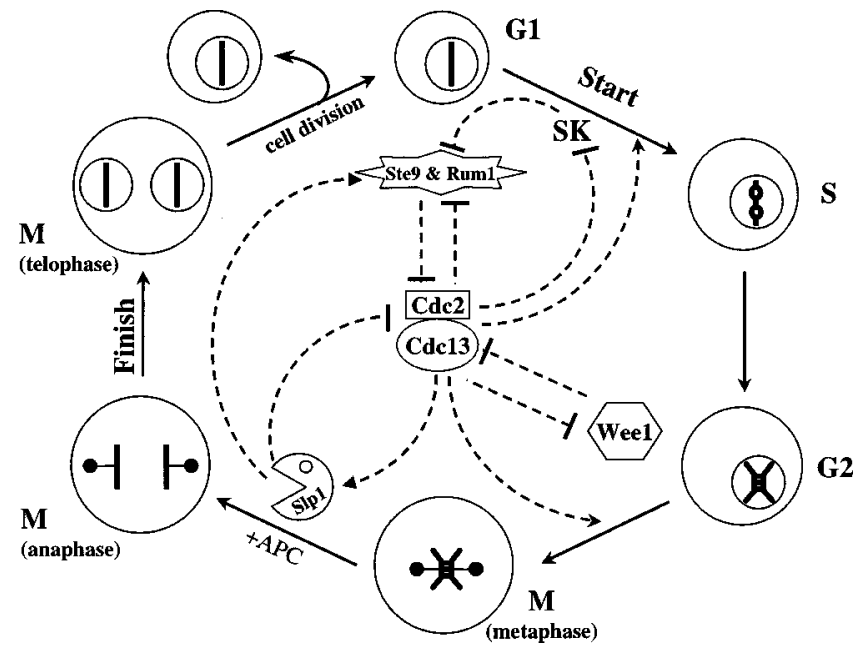

FIG. 1. The eukaryotic cell division cycle. The outside circle shows the major steps of DNA synthesis and mitosis. The inner diagram shows the relationships among the principal molecular components of the cell cycle engine (using fission-yeast terminology).

increases to a higher level in late G2, thereby initiating $\mathrm{M}$ phase. As cells exit $\mathrm{M}$ phase, Cdk activity must be destroyed, to permit accumulation of licensing factors at replication origins in the next G1 phase.

Destruction of Cdk activity as cells exit mitosis is the job of the anaphase promoting complex (APC). The APC is a large protein complex that attaches ubiquitin tags to target proteins, which are then rapidly degraded by proteasomes. ${ }^{9}$ The APC has two important functions at anaphase: (1) to initiate degradation of the cohesion proteins that hold sister chromatids together, thereby initiating mitotic anaphase, and (2) to initiate degradation of B-type cyclins, thereby permitting cells to re-enter $\mathrm{G} 1$ phase.

To recognize the proper substrates for ubiquitination, the APC core requires specific "auxiliary" proteins. Slp1 targets the cohesion complex for disassembly, and both Slp1 and Ste9 present Cdc13 to the APC for ubiquitination. ${ }^{10}$ Proper timing of these events is controlled by phosphorylation and dephosphorylation of Slp1 and Ste9, by Cdk/cyclin complexes and the phosphatases that oppose them.

\section{B. MPF's enemies and friends}

$\mathrm{Cdc} 2 / \mathrm{Cdc} 13$ activity (also called MPF, “M-phase promoting factor'") is controlled by antagonistic interactions with its enemies. ${ }^{11}$ The enemies have negative effects on MPF, but MPF can down-regulate all of its enemies (Fig. 1). Two of these enemies are active in G1 phase, while a different group regulates the $\mathrm{G} 2 / \mathrm{M}$ transition.

The first G1 enemy, Ste9 (also called Srw1), ${ }^{12}$ targets Cdc13 to the APC core and promotes its degradation in G1 (Fig. 2). On the other hand, phosphorylation of Ste9 by MPF inhibits its association with the APC core, rendering it inactive. $^{10}$

The other G1 enemy of MPF is a stoichiometric inhibitor, called Rum1, ${ }^{13}$ which can bind to $\mathrm{Cdc} 2 / \mathrm{Cdc} 13$ complexes and inhibit their activity. ${ }^{14}$ However, phosphorylation of Rum1 by MPF promotes its ubiquitination (by a different

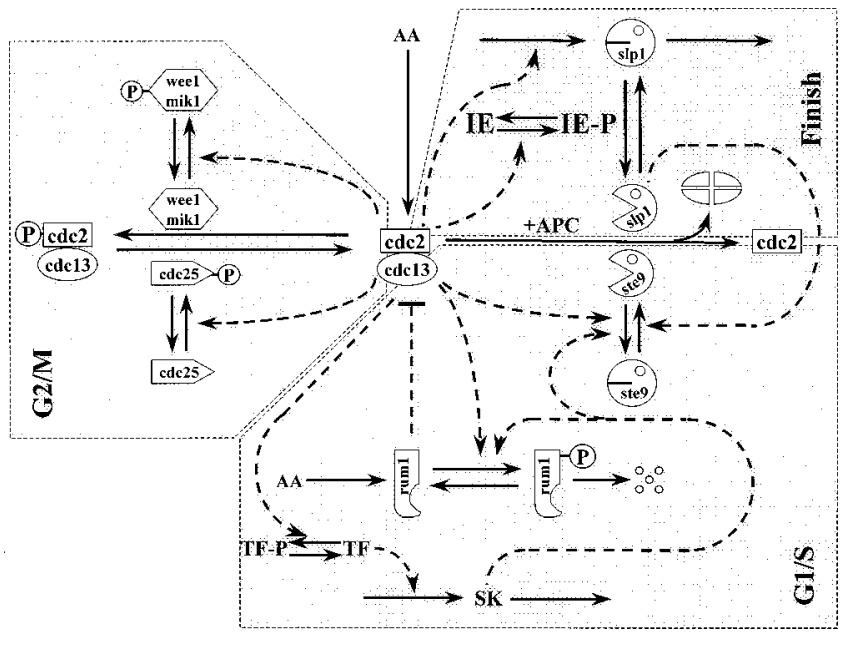

FIG. 2. The wiring diagram of the fission-yeast cell-cycle engine. In the middle of the diagram is $\mathrm{Cdc} 2 / \mathrm{Cdc} 13$ (MPF), which is regulated by proteolysis of the Cdc13 component, phosphorylation of Cdc2 subunit, and stoichiometric inhibition of the complex. These processes are arranged according to the cell cycle transitions in which they are involved.

complex than APC) and rapid degradation. ${ }^{15}$ Hence, there is antagonism between MPF and Rum1, as well as between MPF and Ste9.

Because of these antagonistic relationships, MPF and its G1 enemies cannot coexist. Either the enemies win and the cell is in G1 phase (with low MPF activity), or MPF wins and the cell is in S/G2/M phase of the cycle. ${ }^{11}$ The fight between MPF and its enemies is modulated by helper molecules, which shift the balance in one direction or the other.

The helper molecule for the Start transition $(\mathrm{G} 1 \rightarrow \mathrm{S})$ is a "starter' kinase, a group of Cdk/cyclin complexes (Cdc2 with Cig1, Cig2, and Puc1 cyclins), which help Cdc2/Cdc13 (MPF) to get the upper hand by phosphorylating Rum $1^{16}$ and Ste9. The starter kinases can help MPF because they are less sensitive to Rum1 inhibition and Ste9-dependent ubiquitination. The helper molecule for the Finish transition $(\mathrm{M} \rightarrow \mathrm{G} 1)$ is the Slp1/APC complex, which promotes the degradation of Cdc13 and activates Ste9 (possibly by activating the phosphatase that activates Ste9). Slp1 can help the enemies because it is not inactivated by MPF phosphorylation, as is Ste9. In fact, Slp1 seems to be activated in an MPFdependent manner.

The duration of $\mathrm{G} 2$ phase is regulated by a different mechanism, namely enzymatic inhibition of MPF activity. The active site of $\mathrm{Cdc} 2$ contains a phosphorylatable tyrosine residue, and its tyrosine-phosphorylated form is inactive. ${ }^{4}$ Two tyrosine kinases can inactivate Cdc2 in this way, Wee 1 and Mik1. ${ }^{17,18}$ In return, MPF can also phosphorylate and inactivate them. ${ }^{19}$ So we have another case of mutual antagonism and alternative steady states: an S/G2 state (plenty of tyrosine-phosphorylated $\mathrm{Cdc} 2 / \mathrm{Cdc} 13$, with enough activity to support DNA synthesis but not mitosis) and an M state (inactive Wee1 and Mik1, lots of highly active Cdc2/Cdc13, cell in mitosis).

The G2/M transition is accelerated by a direct positive feedback loop. The inhibitory phosphate group of $\mathrm{Cdc} 2$ is removed by a specific phosphatase, called $\mathrm{Cdc} 25 .{ }^{20} \mathrm{Cdc} 25$ is 
also phosphorylated by MPF, but the phosphorylated form of Cdc25 is more active. ${ }^{20}$ In this case, MPF helps its friend, Cdc25.

\section{Negative feedback loops}

For cells to proliferate, to make a repetitive sequence of properly controlled Start, G2/M and Finish transitions, the helper molecules must be removed after they have done their jobs, because they are inhibitory for the next cell cycle transition. For instance, the starter kinase must disappear after the Start transition; otherwise, it would inhibit the Finish transition, when the enemies of MPF must come back. In fission yeast, regulation of the starter kinases ( $\mathrm{Cdc} 2$ with Cig1, Cig2, and Puc1) is complex and not yet fully understood. For simplicity, we lump them together and assume that MPF inhibits the synthesis of "SK" by phosphorylating its transcription factor (TF).

Slp1 must disappear after the Finish transition; otherwise, it would inhibit the next Start transition. In budding yeast, both synthesis and activation of the Slp1 homologue (Cdc20) is MPF dependent, which creates a negative feedback loop. ${ }^{21} \mathrm{We}$ assume that a similar negative feedback loop is operating in fission yeast. It is essential that Slp1/ APC is not directly activated by MPF, but rather through an intermediary enzyme (IE), which provides a time delay in the loop. ${ }^{22}$ This delay is necessary to give enough time for the chromosomes to align before Slp1/APC breaks down their cohesions. ${ }^{9}$

\section{Surveillance mechanisms}

These helper molecules (and therefore the transitions) are regulated by surveillance mechanisms (also called checkpoints). ${ }^{23}$ Start is controlled by cell mass, Finish by the state of the cell's chromosomes, and the G2/M transition is affected by both.

The chromosome cycle, regulated by the cell cycle engine, must run in concert with overall cytoplasmic growth, to avoid cells becoming hopelessly small or enormously large. ${ }^{24}$ Without such a coordinating mechanism, cells cannot be kept alive over the long term. In fact, mutant fission yeast cells lacking this coordination die because they become either too large $\left(c d c 2^{-}\right)$or too small (wee $1^{-}$rum $1 \Delta$ ).

How cytoplasmic mass exerts its control over the cell cycle engine is not clear at present. The simplest hypothesis is that $\mathrm{Cdk} /$ cyclin complexes accumulate in the nucleus where their (nuclear) concentration will be proportional to the rate of cyclin synthesis in the cytoplasm, which increases as the cell grows. ${ }^{24}$ Although, in principle, both G1/S and G2/M transitions are regulated by size requirements, only one of these controls is operative during steady-state growth and division. In wild-type fission yeast, the G1/S size requirement is much smaller than the G2/M requirement; hence, cells are born with a size larger than necessary for the Start transition. They execute Start soon after division, and their dependence on size is manifested at the G2/M transition only. In wee $1^{-}$mutants, the size requirement for entry into $\mathrm{M}$ phase is abrogated, and these cells exhibit size control at
G1/S. Both size requirements are destroyed in wee $1^{-}$rum $1 \Delta$ mutant cells, which become smaller at each cell division until they die. ${ }^{13}$

The G2/M transition is also controlled by the replication state of the chromosomes. If the DNA is not fully replicated, then MPF stays in the tyrosine-phosphorylated form, which does not let the cell enter $\mathrm{M}$ phase. ${ }^{25}$ This is achieved by signal transduction pathways that activate Wee1 and Mik1 and inhibit Cdc25. ${ }^{26}$

The activity of Slp1 (the helper for Finish) is regulated by a metaphase surveillance mechanism: as long as chromosomes are not properly aligned on the metaphase plate, Slp1 is kept inactive by a Mad2-dependent signal transduction pathway. ${ }^{27}$

These two surveillance mechanisms (unreplicated DNA and misaligned chromosomes) are not essential during the normal cycle. ${ }^{1}$ Both DNA replication and chromosome alignment are normally completed before the cell cycle engine initiates the subsequent step of the cycle. Hence, mutations in these surveillance mechanisms do not harm cells during normal growth and division. However, if chromosome replication or alignment is slowed down or stopped (by drugs or mutations), then the surveillance mechanisms become essential. They guarantee that the cell cycle engine is blocked under these abnormal conditions. If the surveillance mechanisms are compromised, then the cell divides with unreplicated or misaligned chromosomes, which is a lethal mistake.

\section{A SIMPLE MODEL FOR THE FISSION YEAST CELL CYCLE}

The molecular mechanism described in Sec. I can be summarized in a schematic wiring diagram (Fig. 2). In Table I, we convert the wiring diagram into a set of differential and algebraic equations. To keep the model simple, we assume that a number of dynamic variables are in pseudosteady state: (1) the TF for synthesis of the starter kinase (SK), (2) the trimeric complexes of Rum1 and $\mathrm{Cdc} 13 / \mathrm{Cdc} 2$, and (3) the tyrosine modifying enzymes (Wee1 and Cdc25). We assume that Rum 1 binds to both types of $\mathrm{Cdc} 2 / \mathrm{Cdc} 13$ dimers: unphosphorylated (MPF) and phosphorylated (preMPF) (see Fig. 3). The model is similar to a generic picture of eukaryotic cell-cycle controls we have described recently. ${ }^{24}$

\section{A. Numerical simulations \\ 1. Wild-type cells}

Figure 4 presents a numerical solution of the model equations (Table I) with parameter values (Table II) chosen to describe wild-type fission yeast. Cell mass increases exponentially from one to two between birth and cell division. We divide cell mass by two at the end of mitosis, when MPF decreases through 0.1 , although daughter cells do not physically separate from one another until 15-20 min after exit from mitosis.

The MPF level fluctuates during the cycle among three different levels. Cells enter mitosis with high MPF activity. After a time delay, Slp1/APC is activated by the high MPF activity, initiating the degradation of Cdc13. As a consequence, MPF activity drops, Ste9/APC activates, and Cdc13 
TABLE I. The differential and algebraic equations describing the wiring diagram in Fig. 2.

$$
\begin{aligned}
& \frac{d\left[\mathrm{Cdc} 13_{T}\right]}{d t}=k_{1} M-\left(k_{2}^{\prime}+k_{2}^{\prime \prime}[\mathrm{Ste} 9]+k_{2}^{\prime \prime \prime}[\mathrm{Slp} 1]\right)\left[\mathrm{Cdc} 13_{T}\right], \\
& \frac{d[\mathrm{preMPF}]}{d t}=k_{\text {wee }}\left(\left[\mathrm{Cdc} 13_{T}\right]-[\mathrm{preMPF}]\right)-k_{25}[\mathrm{preMPF}]-\left(k_{2}^{\prime}\right. \\
& \left.+k_{2}^{\prime \prime}[\text { Ste9 }]+k_{2}^{\prime \prime \prime}[\operatorname{Slp} 1]\right)[\text { preMPF }], \\
& \frac{d[\mathrm{Ste} 9]}{d t}=\left(k_{3}^{\prime}+k_{3}^{\prime \prime}[\mathrm{Slp} 1]\right) \frac{1-[\mathrm{Ste} 9]}{J_{3}+1-[\mathrm{Ste} 9]}-\left(k_{4}^{\prime}[\mathrm{SK}]\right. \\
& \left.+k_{4}[\mathrm{MPF}]\right) \frac{[\mathrm{Ste} 9]}{J_{4}+[\mathrm{Ste} 9]}, \\
& \frac{d\left[\mathrm{Slp}_{T}\right]}{d t}=k_{5}^{\prime}+k_{5}^{\prime \prime} \frac{[\mathrm{MPF}]^{4}}{J_{5}^{4}+[\mathrm{MPF}]^{4}}-k_{6}\left[\mathrm{Slp}_{T}\right], \\
& \frac{d[\mathrm{Slp} 1]}{d t}=k_{7}[\mathrm{IEP}] \frac{\left[\mathrm{Slp}_{T}\right]-[\mathrm{Slp} 1]}{J_{7}+\left[\mathrm{Slp}_{T}\right]-[\mathrm{Slp} 1]} \\
& -k_{8} \frac{[\operatorname{Slp} 1]}{J_{8}+[\operatorname{Slp} 1]}-k_{6}[\operatorname{Slp} 1] \text {, } \\
& \frac{d[\mathrm{IEP}]}{d t}=k_{9}[\mathrm{MPF}] \frac{1-[\mathrm{IEP}]}{J_{9}+1-[\mathrm{IEP}]}-k_{10} \frac{[\mathrm{IEP}]}{J_{10}+[\mathrm{IEP}]}, \\
& \frac{d\left[\operatorname{Rum}_{T}\right]}{d t}=k_{11}-\left(k_{12}+k_{12}^{\prime}[\mathrm{SK}]+k_{12}^{\prime \prime}[\mathrm{MPF}]\right)\left[\operatorname{Rum}_{T}\right], \\
& \frac{d[\mathrm{SK}]}{d t}=k_{13}[\mathrm{TF}]-k_{14}[\mathrm{SK}] \text {, } \\
& \frac{d M}{d t}=\mu M,
\end{aligned}
$$

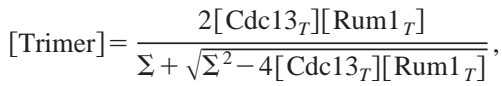

$$
\begin{aligned}
& {[\mathrm{MPF}]=\frac{\left(\left[\mathrm{Cdc} 13_{T}\right]-[\mathrm{preMPF}]\right)\left(\left[\mathrm{Cdc} 13_{T}\right]-[\text { Trimer }]\right)}{\left[\mathrm{Cdc} 13_{T}\right]},} \\
& {[\mathrm{TF}]=G\left(k_{15} M, k_{16}^{\prime}+k_{16}^{\prime \prime}[\mathrm{MPF}], J_{15}, J_{16}\right) \text {, }} \\
& \text { where } \\
& k_{\text {wee }}=k_{\text {wee }}^{\prime}+\left(k_{\text {wee }}^{\prime \prime}-k_{\text {wee }}^{\prime}\right) G\left(V_{\text {awee }}, V_{\text {iwee }}[\mathrm{MPF}], J_{\text {awee }}, J_{\text {iwee }}\right) \text {, } \\
& k_{25}=k_{25}^{\prime}+\left(k_{25}^{\prime \prime}-k_{25}^{\prime}\right) G\left(V_{a 25}[\mathrm{MPF}], V_{i 25}, J_{a 25}, J_{i 25}\right) \text {, } \\
& \Sigma=\left[\operatorname{Cdc} 13_{T}\right]+\left[\operatorname{Rum}_{T}\right]+K_{\text {diss }} \text {, } \\
& G(a, b, c, d)=\frac{2 a d}{b-a+b c+a d+\sqrt{(b-a+b c+a d)^{2}-4 a d(b-a)}}
\end{aligned}
$$

degradation accelerates. Loss of MPF relieves the inhibition on the TF responsible for the synthesis of the cyclin subunit of the SK. Because newborn wild-type cells are already large enough to pass Start, they activate the TF for SK after a very short G1 phase. Consequently, the level of SK increases abruptly and the G1 enemies of MPF (Ste9/APC and Rum1) cannot stay. Actually, G1 is so short that Rum1 does not have time to come up, which is consistent with experimental observations. ${ }^{14}$ As soon as Ste9 gets inactivated, the Cdc13 level rises and the cell passes the G1/S transition. However, SK does not inactivate the third enemy, Wee1, which phosphorylates $\mathrm{Cdc} 2 / \mathrm{Cdc} 13$. The phosphorylated form has reduced protein-kinase activity, which seems to be enough to initiate $\mathrm{S}$ phase but not mitosis. When the cell reaches a critical size, the positive feedbacks for G2/M transition turn on. Abrupt activation of MPF by $\mathrm{Cdc} 25$ drives the cell into mitosis.

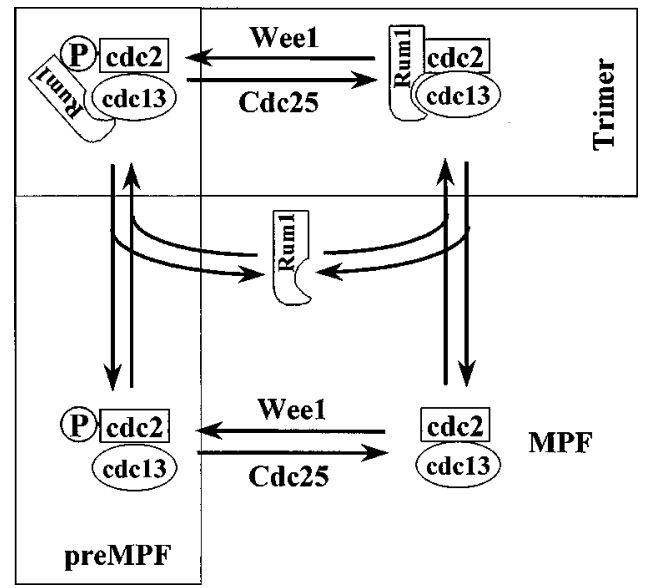

FIG. 3. Rum1 binding to $\mathrm{Cdc} 2 / \mathrm{Cdc} 13$ dimers. We assume that Rum1 binds to both active (MPF) and tyrosine-phosphorylated $\mathrm{Cdc} 2 / \mathrm{Cdc} 13$ dimers. If association and dissociation of trimeric species is rapid, then Eq. (10) describes the equilibrium concentration of the total pool of trimers in terms of the total pools of $\mathrm{Cdc} 13$ and Rum1. The sum of the dimeric and trimeric tyrosine-phosphorylated forms is called preMPF.

The G1 enemies (Rum1 and Ste9) are not essential in wild-type cells, as shown by the viability of rum $1 \Delta$ ste $9 \Delta$ double-mutant cells. ${ }^{10}$ If we remove both Rum1 synthesis and Ste9-mediated Cdc13 degradation from the model $\left(k_{11}\right.$ $=k_{2}^{\prime \prime}=0$ ), then simulated double-mutant cells cycle with slightly smaller mass than wild type (simulations not shown).

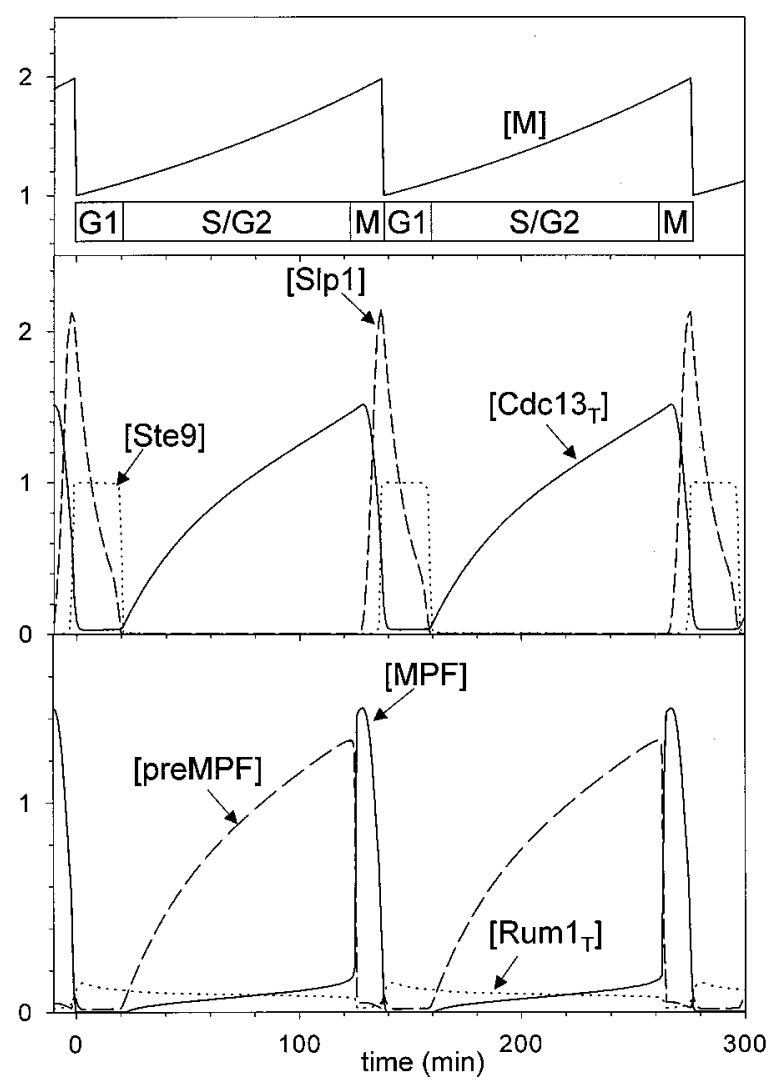

FIG. 4. Numerical simulation of wild-type cell cycle. The equations in Table I are solved, using the parameter values in Table II. Two cell cycles are shown. 
TABLE II. Parameter values for wild-type cells. All constants have units $\mathrm{min}^{-1}$, except the $J \mathrm{~s}$, which are dimensionless Michaelis constants, and $K_{\text {diss }}$, which is a dimensionless equilibrium constant for trimer dissociation.

Cdc13 synthesis and degradation:

$k_{1}=0.03, k_{2}^{\prime}=0.03, k_{2}^{\prime \prime}=1, k_{2}^{\prime \prime \prime}=0.1$.

Ste9 activation and inactivation:

$k_{3}^{\prime}=1, k_{3}^{\prime \prime}=10, J_{3}=0.01, k_{4}^{\prime}=2, k_{4}=35, J_{4}=0.01$.

Slp1 synthesis, degradation, activation and inactivation:

$k_{5}^{\prime}=0.005, k_{5}^{\prime \prime}=0.3, k_{6}=0.1, J_{5}=0.3$

$k_{7}=1, k_{8}=0.25, J_{7}=0.001, J_{8}=0.001$.

IE activation and inactivation:

$k_{9}=0.1, k_{10}=0.04, J_{9}=0.01, J_{10}=0.01$.

Rum1 synthesis, degradation and inhibition:

$k_{11}=0.1, k_{12}=0.01, k_{12}^{\prime}=1, k_{12}^{\prime \prime}=3, K_{\text {diss }}=0.001$.

SK synthesis and degradation:

$k_{13}=0.1, k_{14}=0.1$.

$\mathrm{TF}$ activation and inactivation:

$k_{15}=1.5, k_{16}^{\prime}=1, k_{16}^{\prime \prime}=2, J_{15}=0.01, J_{16}=0.01$.

Wee1 activation and inactivation:

$V_{\text {awee }}=0.25, V_{\text {iwee }}=1, J_{\text {awee }}=0.01, J_{\text {iwee }}=0.01$.

Cdc25 activation and inactivation:

$V_{a 25}=1, V_{i 25}=0.25, J_{a 25}=0.01, J_{i 25}=0.01$.

Rate of tyr-phosphorylation and dephosphorylation:

$k_{\text {wee }}^{\prime}=0.15, k_{\text {wee }}^{\prime \prime}=1.3, k_{25}^{\prime}=0.05, k_{25}^{\prime \prime}=5$.

Growth rate:

$\mu=0.005$.

\section{2. wee1- mutants}

The rate-limiting step in the wild-type cell cycle is down-regulation of Wee1 by MPF. In order to inactivate Wee1, cells must grow to a critical size, which necessitates an extended $\mathrm{S}+\mathrm{G} 2$ phase $(100 \mathrm{~min})$ in their cycle. If Wee1 activity (expressed in $k_{\text {wee }}^{\prime}$ and $k_{\text {wee }}^{\prime \prime}$ ) is reduced, ${ }^{28}$ then cells are advanced into mitosis, dividing at a smaller size than wild-type cells (Fig. 5). This is the defining characteristic of "wee" mutants. ${ }^{29}$

The G2/M transition in wee mutants is not size controlled. Consequently, the length of $\mathrm{S}+\mathrm{G} 2$ phase (with intermediate MPF activity) is much shorter in wee $1^{-}$cells (45 min) than in wild type. To adjust their cycle time to the mass doubling time (140 min), wee $1^{-}$cells have an extended G1 phase, stabilized by up-regulation of Rum1 and Ste9.

Viability of wee $1^{-}$mutants depends on these G1 enemies of Cdk activity. If either rum $1^{13}$ or ste $9^{10}$ is deleted in a wee $1^{-}$background, then cells divide faster than they grow, getting smaller and smaller each cycle until they die. The model presented in this paper is not consistent with these experimental observations, because of the simplifying assumptions we made about the starter kinases. In the model, SK is unaffected by Rum1 and Ste9, and consequently the double mutants (wee $1^{-}$rum $1 \Delta$ and wee $1^{-}$ste $9 \Delta$ ) have the same phenotype as wee $1^{-}$. In reality, Cig2 is partially inhibited by Rum1 and possibly degraded by Ste9. Hence, the double mutants are expected to have increased SK activity and to divide at much smaller size even than wee $1^{-}$ mutants; presumably, they are too small to be viable.

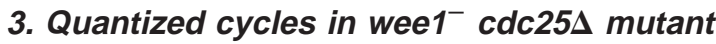

Wee1 and Cdc25 are the major tyrosine-modifying enzymes in fission yeast. If Wee1 (the inhibitor) is missing,

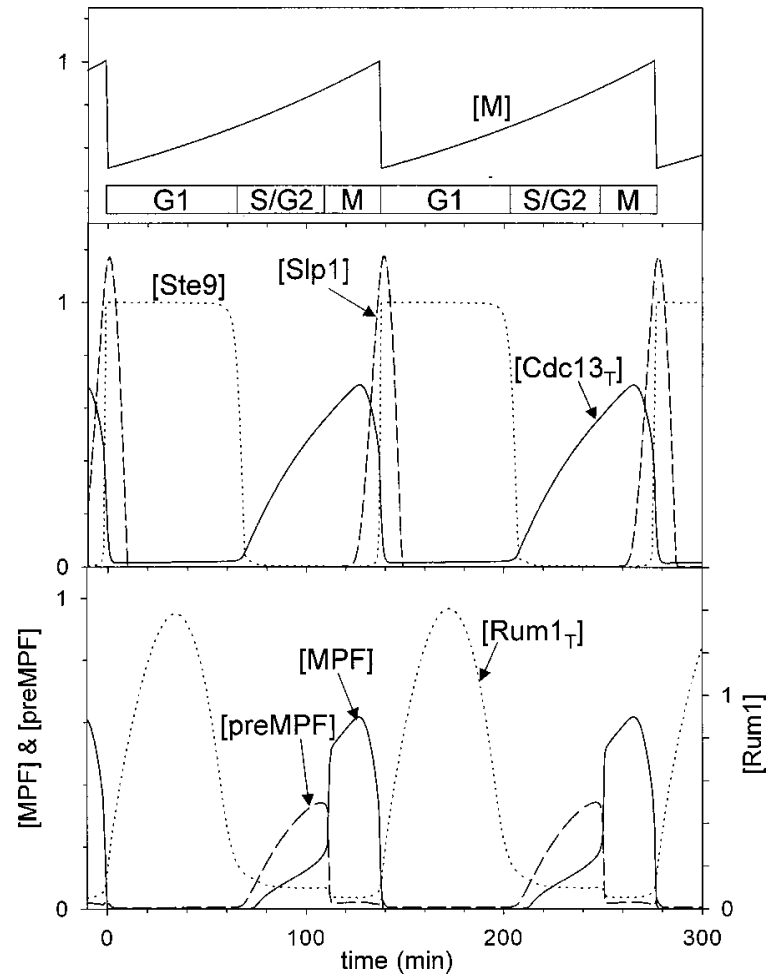

FIG. 5. Numerical simulation of wee $1^{-}$cell cycle. As Fig. 4, except $k_{\text {wee }}^{\prime \prime}$ $=0.3$.

then cells should not need $\mathrm{Cdc} 25$ (the activator). Indeed, wee $1^{-}$cdc $25 \Delta$ double-mutant cells are viable, but they exhibit abnormal progression through the cell cycle. Instead of the usual unimodal distribution of interdivision times, Sveiczer et $a .^{30}$ observed that a steady-state culture of these mutant yeast cells consists of three subpopulations with distinctly different cycle times $(90,160$, and $230 \mathrm{~min})$. In this culture, cycle time appears to be "quantized" in intervals of $70 \mathrm{~min}$. Cells smaller at birth tended to have longer cycle times.

To understand the behavior of wee $1^{-} c d c 25 \Delta$ double mutants, we have taken into account that $\mathrm{Cdc} 25$ has a backup enzyme, called Pyp3, which is a tyrosine-phosphatase with much smaller activity than $\mathrm{Cdc} 25 .^{31}$ As a consequence, in the absence of $\mathrm{Cdc} 25$, the rate constants for $\mathrm{Cdc} 13 / \mathrm{Cdc} 2$ dephosphorylation are small but not zero. Numerical simulation of wee $1^{-} c d c 25 \Delta$ mutants, with $k_{\text {wee }}^{\prime}=0.15, k_{\text {wee }}^{\prime \prime}=0.3$ (for wee $1^{-}$) and $k_{25}^{\prime}=k_{25}^{\prime \prime}=0.02$ (for $c d c 25 \Delta$ ), is shown in Fig. 6. In this simulation, cells alternate between short cycles (100 min) and long cycles (160 min). As observed experimentally, the mutant cells always divide at size larger than wild type. Cells born at the larger size are committed to the shorter cycle, and smaller newborns have longer cycles.

Intuitively, we might explain these quantized cycles as follows. In the mutant cells (lacking Wee1 and Cdc25), the positive feedback loop in mitotic control is missing or very weak. Hence, MPF is not activated abruptly when cells are supposed to enter the M phase. Because MPF rise is sluggish, it may not turn on fully the exit-from-mitosis pathway. In this case, the negative feedback loop generates a rebound in MPF activity before the cell is able to divide. On the 


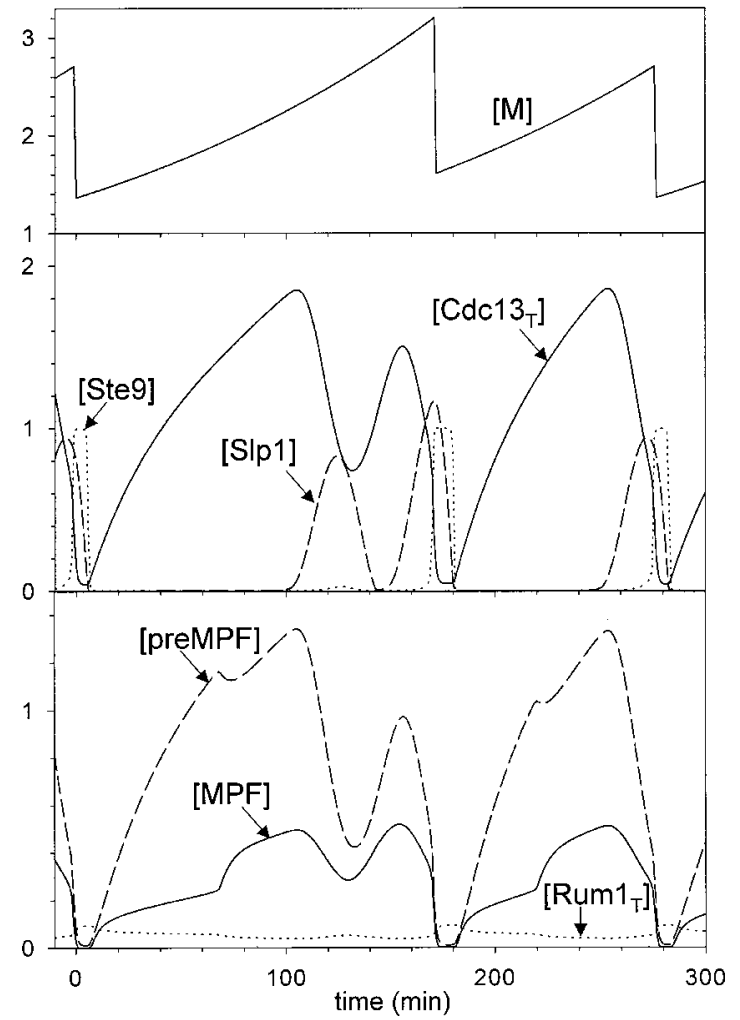

FIG. 6. Numerical simulation of wee $1^{-} c d c 25 \Delta$ cell cycle. As Fig. 4, except $k_{\text {wee }}^{\prime \prime}=0.3, k_{25}^{\prime \prime}=0.02$.

"second try," when its size is larger, the cell successfully completes mitosis.

\section{B. Phase-plane portraits and bifurcation analysis}

The model, with nine ordinary differential equations (ODEs), can be represented in the phase plane, Cdc13 $3_{T}$ vs MPF, in the following way. First, we treat cell mass $(M)$ as a parameter, and we assume that the dynamic variables described by Eqs. (3)-(8) (Table I) are in steady state. Our goal is to express the steady-state values of these variables as functions of [MPF] and $M$ :

$$
\begin{aligned}
{[\mathrm{SK}] } & =\left(k_{13} / k_{14}\right)[\mathrm{TF}] \\
& =\left(k_{13} / k_{14}\right) G\left(k_{15} M, k_{16}^{\prime}+k_{16}^{\prime \prime}[\mathrm{MPF}], J_{15}, J_{16}\right),
\end{aligned}
$$

$\left[\operatorname{Rum}_{T}\right]=\frac{k_{11}}{k_{12}+k_{12}^{\prime}[\mathrm{SK}]+k_{12}^{\prime \prime}[\mathrm{MPF}]}$,

$[\mathrm{IEP}]=G\left(k_{9}[\mathrm{MPF}], k_{10}, J_{9}, J_{10}\right)$,

$\left[\operatorname{Slp} 1_{T}\right]=\frac{k_{5}^{\prime}}{k_{6}}+\frac{k_{5}^{\prime \prime}}{k_{6}} \cdot \frac{[\mathrm{MPF}]^{4}}{J_{5}^{4}+[\mathrm{MPF}]^{4}}$,

$[\mathrm{Slp} 1]=\left[\mathrm{Slp} 1_{T}\right] G\left(k_{7}[\mathrm{IEP}], k_{8}, J_{7} /\left[\mathrm{Slp} 1_{T}\right], J_{8} /\left[\mathrm{Slp} 1_{T}\right]\right)$,

$[\mathrm{Ste} 9]=G\left(k_{3}^{\prime}+k_{3}^{\prime \prime}[\mathrm{Slp} 1], k_{4}^{\prime}[\mathrm{SK}]+k_{4}^{\prime \prime}[\mathrm{MPF}], J_{3}, J_{4}\right)$.

In these equations, $G\left(V_{a}, V_{b}, J_{a}, J_{b}\right)$ is the GoldbeterKoshland function ${ }^{32}$ defined in Table I. Also, in order to obtain an analytical expression for [Slp1], we have neglected the degradation term, $k_{6}[\mathrm{Slp} 1]$, compared to the posttranslational modification terms; hence, our phase-plane portraits will be only approximately correct.

At this point, we are left with only Eqs. (1) and (2) in Table I. From Eq. (1) we can define a $\mathrm{Cdc} 13_{T}$ nullcline

$$
\left[\mathrm{Cdc} 13_{T}\right]=\frac{k_{1} M}{k_{2}^{\prime}+k_{2}^{\prime \prime}[\mathrm{Ste} 9]+k_{2}^{\prime \prime \prime}[\mathrm{S} \operatorname{lp} 1]},
$$

where the rate of Cdc13 synthesis, $k_{1} M$, is exactly balanced by its rate of degradation. The $\mathrm{Cdc} 13_{T}$ nullcline can now be calculated explicitly as a function MPF, from the equations for [Ste9] and [Slp1] directly before.

From Eq. (2) we derive a second nullcline

$$
\begin{aligned}
{\left[\mathrm{Cyc}_{13}\right]=} & \left(1+\frac{k_{25}+k_{2}^{\prime}+k_{2}^{\prime \prime}[\text { Ste9 }]+k_{2}^{\prime \prime \prime}[\operatorname{Slp} 1]}{k_{\text {wee }}}\right) \\
& \times[\text { preMPF }]
\end{aligned}
$$

where the rate of preMPF formation, $k_{\text {wee }}\left(\left[\mathrm{Cdc} 13_{T}\right]\right.$ $-[$ preMPF $])$, is exactly balanced by the rate of degradation and dephosphorylation of preMPF. We want to express this nullcline in terms of $[\mathrm{MPF}]$ rather than [preMPF]. Notice that, by definition

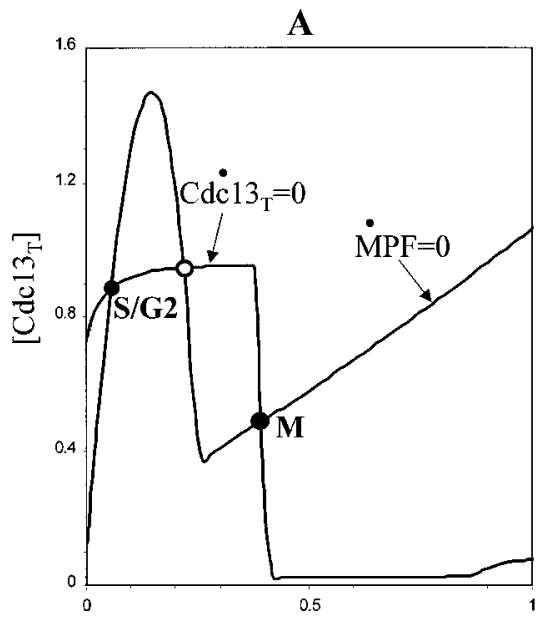

[MPF]

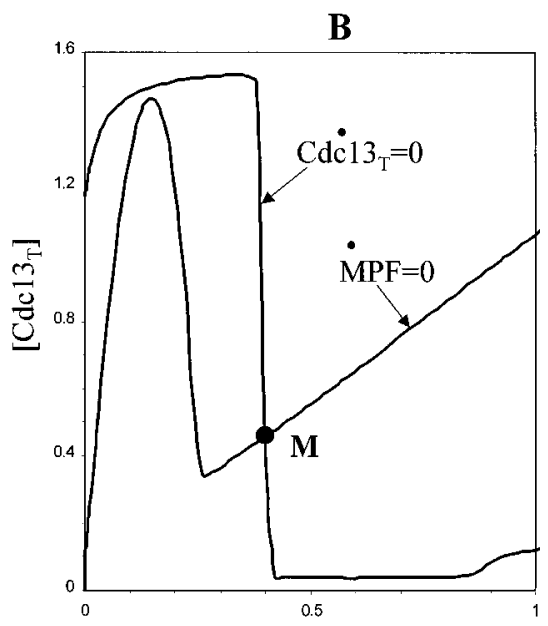

[MPF]
FIG. 7. Phase planes portraits for wild-type cells. MPF-Cdc13 $3_{T}$ phase planes are shown for (a) newborn cells $(M=1)$ and (b) cells just past the $\mathrm{G} 2 \rightarrow \mathrm{M} \quad$ transition $\quad(M=1.6)$. $\boldsymbol{O}=$ stable steady state; $O=$ unstable steady state. 
$\left[\mathrm{Cdc}_{3} 3_{T}\right]=[\mathrm{Cdc} 2: \mathrm{Cdc} 13]+[\mathrm{PCdc} 2: \mathrm{Cdc} 13]$

$$
+[\text { Cdc2:Cdc13:Rum1] }+[\text { PCdc2:Cdc13:Rum1 }] \text {, }
$$

where $\quad[\mathrm{MPF}]=[\mathrm{Cdc} 2: \mathrm{Cdc} 13]$ and $[\mathrm{preMPF}]$ $=[\mathrm{PCdc} 2: \mathrm{Cdc} 13]+[\mathrm{PCdc} 2: \mathrm{Cdc} 13: \mathrm{Rum} 1]$ Along the nullcline given by Eq. (B), we can write this identity as

$$
\begin{aligned}
{\left[\mathrm{Cdc}_{1} 3_{T}\right]=} & {[\mathrm{MPF}]\left(1+\frac{k_{\text {wee }}}{k_{25}+k_{2}^{\prime}+k_{2}^{\prime \prime}[\mathrm{Ste} 9]+k_{2}^{\prime \prime \prime}[\mathrm{Slp} 1]}\right) } \\
& \times\left(1+\frac{[\mathrm{Cdc} 2: \mathrm{Cdc} 13: \mathrm{Rum} 1]}{[\mathrm{MPF}]}\right) .
\end{aligned}
$$

Assuming that dimers and trimers are in rapid equilibrium

$$
\begin{aligned}
\frac{[\mathrm{Cdc} 2: \mathrm{Cdc} 13: \mathrm{Rum} 1]}{[\mathrm{MPF}]} & =\frac{[\mathrm{Rum} 1]}{K_{\mathrm{diss}}} \\
& =\frac{\left[\mathrm{Rum}_{T}\right]}{K_{\mathrm{diss}}+[\mathrm{MPF}]\left(1+\frac{k_{\text {wee }}}{k_{25}+k_{2}^{\prime}+\ldots}\right)},
\end{aligned}
$$

where the last equality comes from the fact that

$$
\begin{aligned}
{\left[\operatorname{Rum}_{T}\right]=} & {[\text { Rum } 1]+[\mathrm{MPF}]\left(\frac{[\operatorname{Rum} 1]}{K_{\text {diss }}}\right) } \\
& \times\left(1+\frac{k_{\text {wee }}}{k_{25}+k_{2}^{\prime}+k_{2}^{\prime \prime}[\text { Ste } 9]+k_{2}^{\prime \prime \prime}[\text { Slp } 1]}\right) .
\end{aligned}
$$

Hence, Eq. (B) can be written for $\left[\mathrm{Cdc}^{3} 3_{T}\right]$ as an explicit function of $[\mathrm{MPF}]$ :

$$
\begin{aligned}
{\left[\mathrm{Cdc}_{1} 3_{T}\right]=} & {[\mathrm{MPF}]\left(1+\frac{k_{\text {wee }}}{k_{25}+k_{2}^{\prime}+k_{2}^{\prime \prime}[\mathrm{Ste} 9]+k_{2}^{\prime \prime \prime}[\mathrm{Slp} 1]}\right) } \\
& \times\left\{1+\frac{\left[\mathrm{Rum}_{T}\right]}{K_{\mathrm{diss}}+[\mathrm{MPF}]\left(1+\frac{k_{\text {wee }}}{k_{25}+k_{2}^{\prime}+\ldots}\right)}\right),
\end{aligned}
$$

where $\left[\right.$ Rum $\left._{T}\right]$ is a function of $[\mathrm{MPF}]$ alone, from Eqs. (7) and (8) in Table I:

$$
\left[\operatorname{Rum}_{T}\right]=\frac{k_{11}}{k_{12}+k_{12}^{\prime}\left(k_{13} / k_{14}\right) G\left(k_{15} M, k_{16}^{\prime}+k_{16}^{\prime \prime}[\mathrm{MPF}], J_{15}, J_{16}\right)+k_{12}^{\prime \prime}[\mathrm{MPF}]}
$$

\section{Wild-type cells}

The nullclines for a newborn wild-type cell are shown on Fig. 7(a). The MPF nullcline, Eq. (C), is N-shaped, and the $\mathrm{Cdc}_{13}$ nullcline, Eq. (A), sigmoidal-shaped. The nullclines intersect at three steady states: two stable attractors separated by a saddle point. The stable steady state on the left branch of the MPF nullcline corresponds to the S/G2 state, where total Cdc13 level is high but MPF activity is low, indicating that $\mathrm{Cdc} 13 / \mathrm{Cdc} 2$ dimers are mostly tyrosinephosphorylated form, because Wee1 is active and Cdc25 inactive. The steady state on the middle branch is an unstable saddle point. The steady state at high MPF level, on the right branch of the MPF nullcline, represents the mitotic state.

In wild-type cells, all steady states have relatively high Cdc13 level. There is no stable G1 steady state with low Cdc13 level and active Ste9/APC, because wild-type cells are large enough at birth to pass the G1/S transition. ${ }^{25}$ To see this, notice that the transcription factor for SK is on for $M$ $>k_{16}^{\prime} / k_{15}=0.66$, if MPF activity is close to zero (this is a property of the Goldbeter-Koshland function, $G\left(V_{a}, V_{b}, J_{a}, J_{b}\right)$, which switches abruptly between 0 and 1 at $\left.V_{a}=V_{b}\right)$. Because wild-type cells are born at $M=1$, they are large enough to turn on transcription of SK immediately; hence, SK can help Cdc13/Cdc2 to defeat Ste9 and Rum1, so cells do not linger in the G1 phase. This is consistent with experiments, which show that wild-type cells arrest in the G1 phase only if they are nutrient-starved and hence unusually small. ${ }^{33}$

Cell mass $(M)$ can be thought of as a bifurcation parameter in the model. As a newborn cell grows, the $\mathrm{Cdc}^{1} 3_{T}$ nullcline moves up [see Eq. (A) and Fig. 7(b)], and the S/G2 state (a stable node) fuses with the saddle point and disappears. The cell then makes an irreversible transition to the stable mitotic state. Hence, our simplified phase-plane representation of the control system shows clearly how cell size controls the $\mathrm{G} 2 \rightarrow \mathrm{M}$ transition in wild-type fission yeast. But how does the control system exit the mitotic state and return to $\mathrm{G} 1$ at the end of the cycle?

In this phase-plane representation of the system, with all components (except $\mathrm{Cdc}_{13}$ and MPF) in pseudosteady state, the mitotic state is stable. But in the full model (Table I), this steady state is unstable as a consequence of the negative feedback loop: $\mathrm{MPF} \rightarrow \mathrm{IE} \rightarrow \mathrm{Slp} 1 / \mathrm{APC}-\mid \mathrm{MPF}$. To see this, we construct a one-parameter bifurcation diagram (Fig. 8) for ODEs (1)-(8) in Table I, treating mass $(M)$ as a bifurcation parameter. This diagram, showing steady state [MPF] as a function of $M$, exhibits a typical hysteresis loop, with three steady states for $0.423<M<1.55$. (These three steady states correspond to the intersection of the nullclines in Fig. 7 , except the $\mathrm{M}$ state is unstable in the full system of equations.)

The steady state with the highest MPF level is mostly unstable, due to a supercritical Hopf bifurcation at $M$ $=0.548$. The Hopf bifurcation throws off small-amplitude, stable limit cycles, which turn unstable just before they disappear at an infinite-period, saddle-loop bifurcation. These limit cycles have no apparent physiological significance. A newborn cell $(M=1)$ finds itself on the only attracting state (the S/G2 stable steady state). As the cell grows, it approaches the SNIC bifurcation ("saddle-node on an invariant circle") at $M=1.55$. Beyond this bifurcation, in the full 


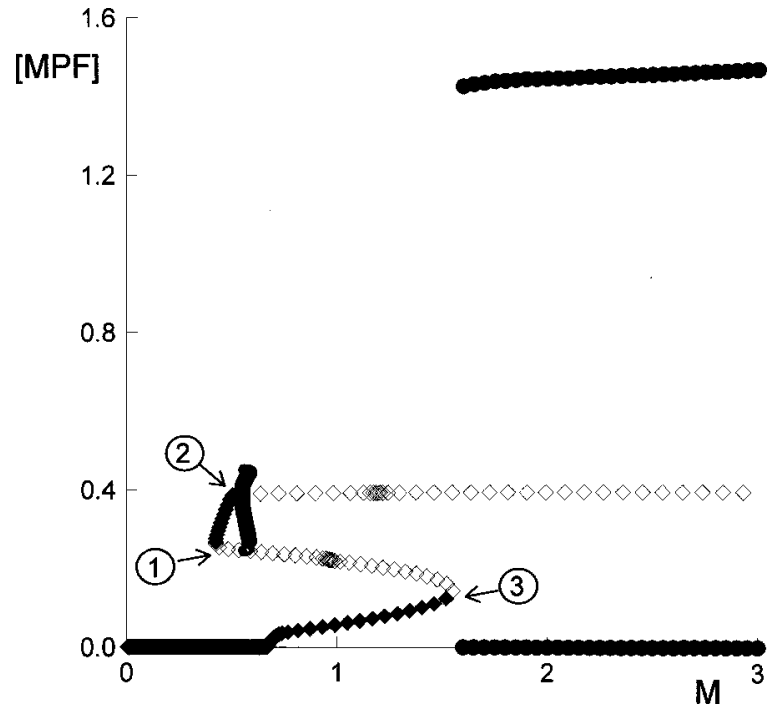

FIG. 8. One-parameter bifurcation diagram for wild-type cells. MPF activity as a function of mass, treated as a bifurcation parameter. Symbols: filled diamond $=$ stable steady state, open diamond $=$ unstable steady state, filled circle $=$ stable limit cycle (maximum and minimum values of MPF), open circle $=$ unstable limit cycle. The principal bifurcations are: (1) saddle-node (SN) at $M=0.423$, (2) Hopf at $M=0.548$, and (3) saddle-node-invariantcycle (SNIC) at $M=1.55$. If we follow the branch of stable limit cycles to larger mass, we find them disappearing at a SNIC bifurcation at $M=13.4$.

model, the only attracting state is a large-amplitude limit cycle. The "mitotic" steady state, which was stable in the phase-plane picture, is unstable in the full model. As the growing cell passes the SNIC bifurcation, its pool of tyrosine-phosphorylated $\mathrm{Cdc} 2 / \mathrm{Cdc} 13$ dimers is activated by $\mathrm{Cdc} 25$. The burst of MPF activity drives the cell into mitosis. The negative feedback loop then destroys Cdc13 and MPF activity drops dramatically as the cell exits mitosis. When [MPF] drops below 0.1, we assume, the cell divides. Since mass is around 2 at this time, the daughter cells are born at $M=1$ and are attracted to the $\mathrm{S} / \mathrm{G} 2$ stable steady state, and the cycle repeats.

\section{2. wee1- cells}

These mutant cells divide at $M=1$, about half the size of wild-type cells. The phase plane for a newborn ( $M$ $=0.5)$ wee $1^{-}$cell shows three steady states [Fig. 9(a)]. The stable state on the left branch of the N-shaped nullcline is at low $\mathrm{Cdc}_{1} 3_{T}$ and low MPF activity (because Ste9 is active and Rum1 level is high) and corresponds to a G1 state of the cycle. The other two steady states are a saddle point and a mitotic state, as in wild type. As the cell grows, the cyclin nullcline moves up, the G1 steady state disappears by coalescing with the saddle point, and the control system is captured by a large-amplitude limit cycle [Fig. 9(b) for the full model], exactly as in wild type. The only difference is that, in wee $1^{-}$cells, all the bifurcations occur at smaller size.

By comparing the bifurcation diagrams for wild-type and wee $1^{-}$cells, we can explain how wild-type cells block in G1 after nutrient starvation. When wild-type cells are starved, they down-regulate Wee1 activity and behave like wee $1^{-}$cells. ${ }^{33}$ Their size is between 1 and 2 , but their dynamics follow the bifurcation diagram of wee $1^{-}$cells. They
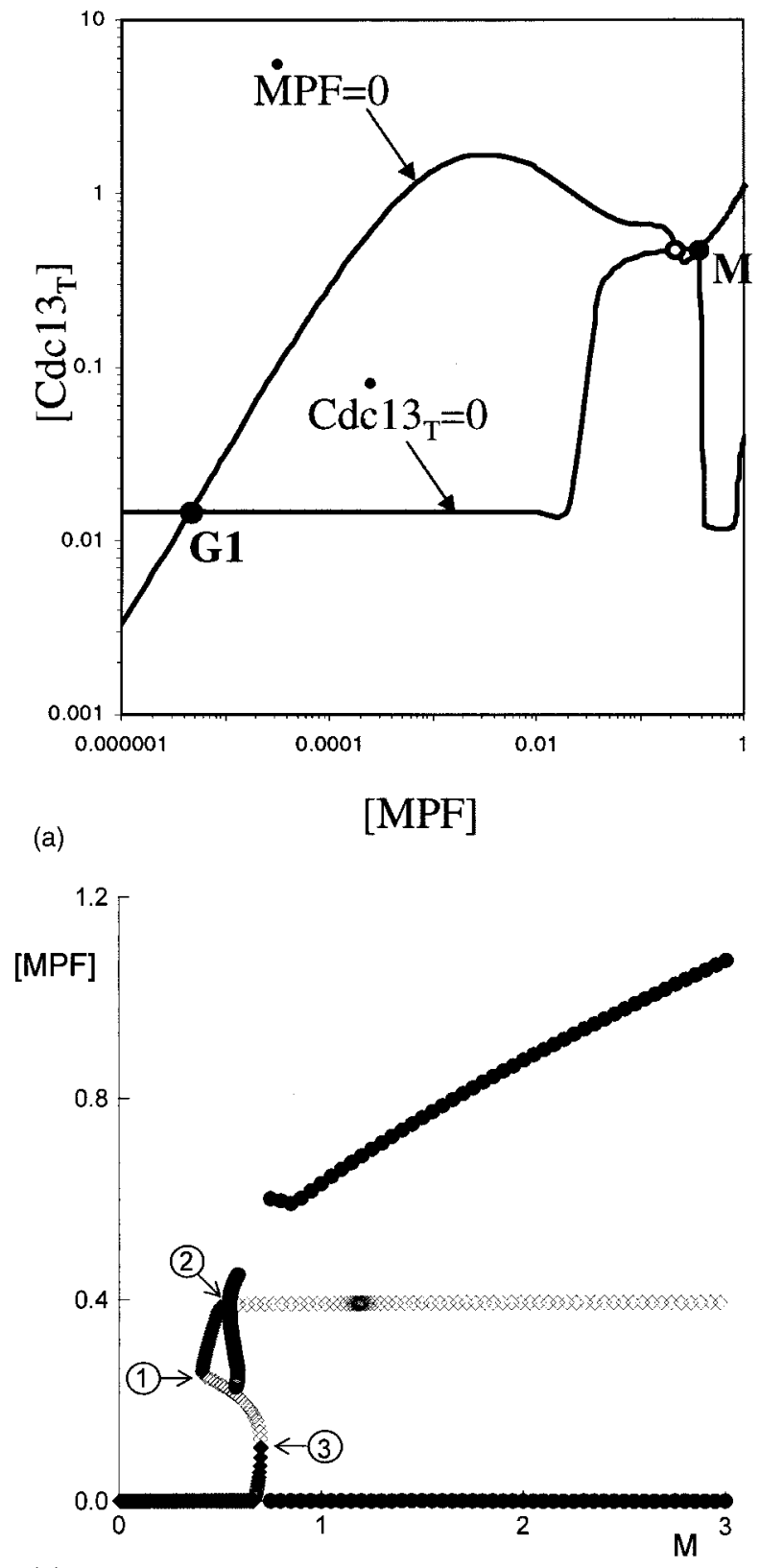

(b)

FIG. 9. Analysis of wee $1^{-}$cell cycle. Parameter values as in Fig. 5. (a) Phase plane portrait for $M=0.5$, as in Fig. 7. (b) Bifurcation diagram, as in Fig. 8. The principal bifurcations are: (1) SN at $M=0.412$, (2) Hopf at $M$ $=0.547$, and (3) SNIC at $M=0.701$.

remain in the oscillatory regime and continue dividing (without further growth) until $M$ drops below 0.7 . Then they stop on the lower branch of the bifurcation diagram, in the stable G1 state of the cycle.

\section{3. wee1 ${ }^{-}$cdc25s cells}

The phase plane for wee $1^{-} c d c 25 \Delta$ cells, as for wildtype cells, does not exhibit a stable G1 steady state [Fig. 10(a)]. For small cells, there are two stable steady states separated by a saddle point. The stable steady state on the left has low MPF activity (because Mik1 activity is on) and it clearly corresponds to a G2 state. The stable steady state on the middle, rising branch has higher MPF activity, pre- 


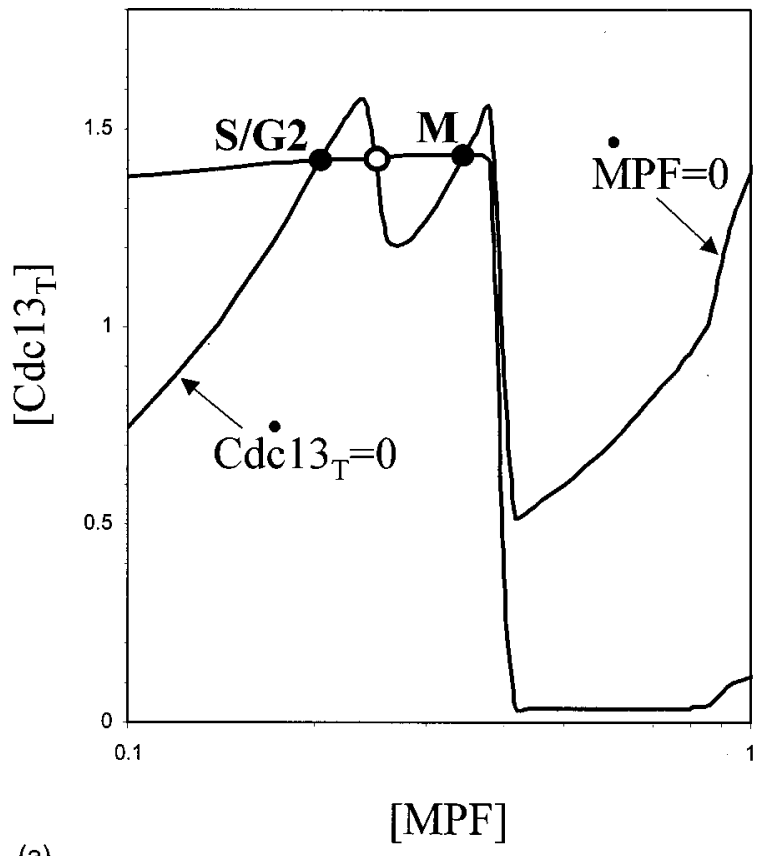

(a)

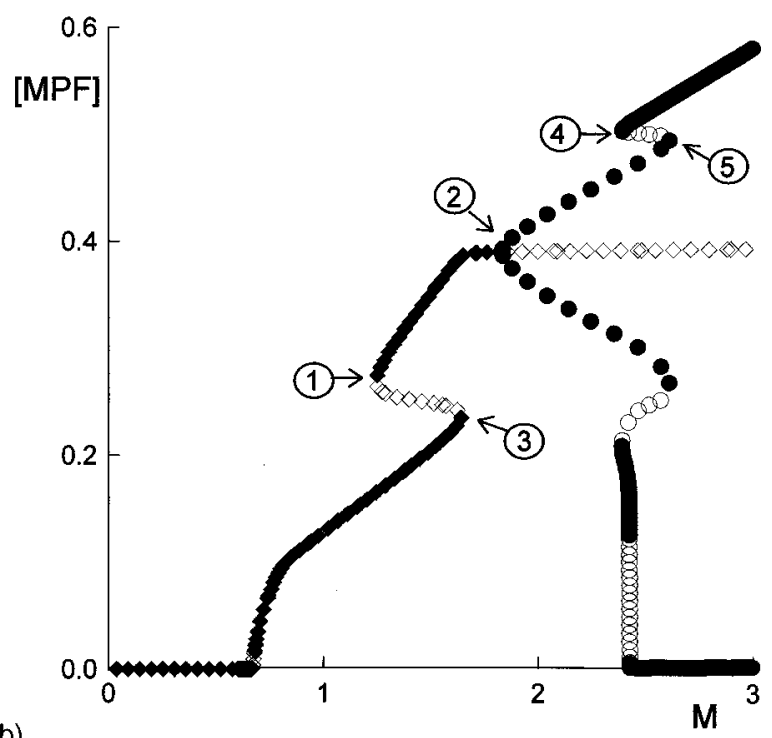

(b)

FIG. 10. Analysis of wee $1^{-} c d c 25 \Delta$ cell cycle. Parameter values as in Fig. 6. (a) Phase plane portrait for $M=1.5$, as in Fig. 7. (b) Bifurcation diagram, as in Fig. 8. The principal bifurcations are: (1) $\mathrm{SN}$ at $M=1.25$, (2) Hopf at $M=1.83$, (3) SN at $M=1.64$, (4) cyclic fold (CF) at $M=2.37$, and (5) $\mathrm{CF}$ at $M=2.60$.

sumably high enough to drive a cell into mitosis. As the cell grows, it loses the stable G2 state by a saddle-node bifurcation and transits to the stable $\mathrm{M}$ state. From the oneparameter bifurcation diagram for the full model [Fig. 10(b)], we see that this bifurcation occurs at $M=1.64$. Since the mitotic state is a stable steady state, the cell enters $M$ phase with no "intention" of leaving. As the cell grows past $M=1.83$, the mitotic steady state loses stability by supercritical Hopf bifurcation. Once the cell passes the Hopf bifurcation point, MPF starts to oscillate, but with small amplitude and nearly constant period. Because $[\mathrm{MPF}]$ may not drop below 0.1 during the first oscillation, the cell may not exit mitosis properly. Rather than dividing, the cell increases further in mass and makes a second, larger amplitude oscillation in [MPF]. Only when cell mass increases past the cyclic-fold bifurcation at $M=2.6$ does [MPF] drop low enough for the cell to leave mitosis. Of course, it is not necessary to make two oscillations in [MPF], as is evident in Fig. 6. If the cell is large enough at birth, the first oscillation will be sufficient to drive it through a normal mitotic sequence.

\section{DISCUSSION}

A major challenge of postgenomic biology is to develop useful theoretical tools for deriving the physiological properties of cells from the "wiring diagrams" of the molecular machines that carry out the essential chores of life. In a series of recent publications, we have illustrated how this connection might be made for one of the most fundamental chores: the cell cycle. This paper concentrates on some nitty-gritty features of cell division in fission yeast and the specific molecules underlying the behavior of wild type and mutant cells. Not to become lost in a forest of details, let us highlight first the overall approach.

(1) View 1. The wiring diagram (Fig. 2) can be abstracted from the literature. It summarizes a vast number of observations and the ideas of many experimentalists about how their molecular components interact. In essence, the wiring diagram is a grand hypothesis about the molecular network controlling cell division in a certain organism. To refute, or confirm, or refine this hypothesis, it must be forced into contact with data, to postdict all the known properties of cell division in the organism and to predict the results of new experiments. But wiring diagrams like Fig. 2, although they are a view of reality that is immediately recognizable by a molecular biologist, cannot be used directly to make reliable, quantitative statements about the behavior of a molecular control system.

(2) View 2. To make such statements, the diagram must be translated into precise mathematical terms: e.g., the system of differential and algebraic equations in Table I. This translation requires a set of auxiliary assumptions about (1) the kinetic forms of the rate equations describing all the steps in the mechanism and (2) the numerical values of the rate constants that parameterize these equations. Once this is done, we have a "machine readable" version of the hypothesis that we can use to compute any desired property of the control system.

(3) View 3. Unfortunately, view No. 2 of reality is completely foreign to experimentalists, and, to tell the truth, hardly recognizable to theoreticians. To see inside the control system, to understand its attributes, to guess intelligently how it will behave under various conditions, we need a third view, a geometrical interpretation of the dynamical system, which is provided by bifurcation theory (Figs. 7-10).

To make the connection between molecules and physiology, we need all three views: the wiring diagram, to see how the molecules are supposedly hooked together; the differential equations, to make reliable, quantitative deductions about the behavior of the hypothetical control system; and 
bifurcation theory, to give us an insider's view of the dynamical potential of the model.

We have used fission yeast as an example, because this organism played a central role in unraveling the molecular machinery of the eukaryotic cell-cycle engine. Paul Nurse's discovery, in 1975, of the wee 1 gene was the crucial first step. ${ }^{29}$ Because wee $1^{-}$cells grow perfectly well but divide at an abnormally small size, Nurse knew that he had a gene intimately involved in the regulation of cell division (rather than the nuts and bolts of DNA replication and sister chromatid segregation). Shortly thereafter, Nurse proved the existence of a dominant mutant allele of $c d c 2$ with the wee phenotype, suggesting that $c d c 2$ also plays a central role in the control system. $^{34}$ When Fantes showed that wee $1^{-} c d c 25 \Delta$ double-mutant cells are viable, ${ }^{35}$ the cellcycle community had a third component of the regulatory network and a good idea of how the pieces fit together.

From this picture (the G2/M box in Fig. 2), we started building mathematical models of fission-yeast cell-cycle control in $1991,{ }^{36}$ adding rum 1 (the G1/S box) in 1997, ${ }^{37}$ and slp 1 ste 9 (Finish) in $2000 .{ }^{38}$ From a dynamical point of view, the most interesting aspect of the problem are the quantized cycles in wee $1^{-} c d c 25 \Delta$ double-mutant cells, which we have emphasized in this paper. The theory proposed here is slightly different from our proposal in Sveiczer et $a l .{ }^{39}$ In that paper, we assumed that Slp1 could not degrade Cdc13 directly, but only indirectly by activating Ste9. Furthermore, we assumed that Mik1 activity could be downregulated by phosphorylation by MPF, exactly as Wee1. In that paper, the small-amplitude oscillations in MPF that generate quantized cell cycles are due to the interactions between MPF and Mik1. In this paper, there is no feedback of MPF on Mik1; the small-amplitude oscillations are generated by a negative feedback in the mechanism (MPF $\rightarrow \mathrm{IEP} \rightarrow$ Ste9- $\| \mathrm{MPF})$. We believe that the present explanation is more likely than the former.

The fact that we have published two quite different explanations of the same phenomenon within one year illustrates both the power and limitations of a theoretical approach to molecular regulatory networks. First, the strength: without such an approach it would be impossible to think at all reliably about the molecular basis of a phenomenon as subtle as quantized cell cycles in fission yeast mutants. Now, the weakness: showing that a mechanistic hypothesis is consistent with observations does not prove that the hypothesis is correct. An alternative hypothesis may work equally well or better. There is nothing novel or unexpected about this weakness; it is a well-known limitation of mechanistic hypothesis testing in chemical kinetics. In molecular cell biology, we must learn to accept the bad news along with the good, because no one has yet come up with a more powerful or less vulnerable way to unravel complex chemical reaction networks.

\section{ACKNOWLEDGMENTS}

The authors thank Kathy Chen for helpful comments on this manuscript. This research was supported by the Howard
Hughes Medical Institute (75195-542501), the Hungarian Scientific Research Fund (OTKA T 032015), and the National Science Foundation (DBI-9724085 and MCB0078920).

${ }^{1}$ A. Murray and T. Hunt, The Cell Cycle (W. H. Freeman, New York, 1993).

${ }^{2}$ K. W. Kohn, Mol. Biol. Cell 10, 2703 (1999).

${ }^{3}$ K. Chen et al., Mol. Biol. Cell 11, 369 (2000).

${ }^{4}$ P. Nurse, Nature (London) 344, 503 (1990).

${ }^{5}$ D. Fisher and P. Nurse, Semin. Cell Biol. 6, 73 (1995); K. Nasmyth, Trends Genet. 12, 405 (1996).

${ }^{6}$ J. Hayles, D. Fisher, A. Woollard, and P. Nurse, Cell 78, 813 (1994).

${ }^{7}$ D. Fisher and P. Nurse, EMBO J. 15, 850 (1996).

${ }^{8}$ B. Stern and P. Nurse, Trends Genet. 12, 345 (1996).

${ }^{9}$ W. Zachariae and K. Nasmyth, Genes Dev. 13, 2039 (1999).

${ }^{10}$ S. Yamaguchi, H. Okayama, and P. Nurse, EMBO J. 19, 3968 (2000); M. Blanco, A. Sanchez-Diaz, J. M. Prada, and S. Moreno, ibid. 19, 3945 (2000).

${ }^{11}$ B. Novak, A. Csikasz-Nagy, B. Gyorffy, K. Nasmyth, and J. J. Tyson, Philos. Trans. R. Soc. London, Ser. B 353, 2063 (1998).

${ }^{12}$ S. Yamaguchi, H. Murakami, and H. Okayama, Mol. Biol. Cell 8, 2475 (1997); K. Kitamura, H. Maekawa, and C. Shimoda, ibid. 9, 1065 (1998).

${ }^{13}$ S. Moreno and P. Nurse, Nature (London) 367, 236 (1994).

${ }^{14}$ J. Correabordes and P. Nurse, Cell 83, 1001 (1995); C. MartinCastellanos, K. Labib, and S. Moreno, EMBO J. 15, 839 (1996).

${ }^{15}$ J. Benito, C. Martin-Castellanos, and S. Moreno, EMBO J. 17, 482 (1998).

${ }^{16}$ C. Martin-Castellanos, M. A. Blanco, J. M. de Prada, and S. Moreno, Mol. Biol. Cell 11, 543 (2000).

${ }^{17} \mathrm{P}$. Russell and P. Nurse, Cell 49, 559 (1987).

${ }^{18} \mathrm{~K}$. Lundgren et al., Cell 64, 1111 (1991).

${ }^{19}$ R. Aligue, L. Wu, and P. Russell, J. Biol. Chem. 272, 13320 (1997).

${ }^{20}$ J. Millar and P. Russell, Cell 68, 407 (1992).

${ }^{21}$ M. Shirayama, W. Zachariae, R. Ciosk, and K. Nasmyth, EMBO J. 17, 1336 (1998).

${ }^{22}$ B. Novak and J. J. Tyson, J. Cell. Sci. 106, 1153 (1993).

${ }^{23}$ K. Nasmyth, Science 274, 1643 (1996).

${ }^{24}$ J. J. Tyson and B. Novak, J. Theor. Biol. (in press).

${ }^{25}$ P. Nurse, Philos. Trans. R. Soc. London, Ser. B 341, 449 (1993).

${ }^{26}$ N. Rhind and P. Russell, Curr. Opin. Cell Biol. 10, 749 (1998).

${ }^{27}$ S. H. Kim, D. P. Lin, S. Matsumoto, A. Kitazono, and T. Matsumoto, Science 279, 1045 (1998)

${ }^{28}$ Since Wee1 has a backup enzyme (Mik1), the rate of tyrosinephosphorylation is not zero in wee $1^{-}$cells; hence, we reduce $k_{\text {wee }}^{\prime \prime}$ from 1.3 to 0.3 for the numerical simulations in Fig. 5 .

${ }^{29}$ P. Nurse, Nature (London) 256, 457 (1975).

${ }^{30}$ A. Sveiczer, B. Novak, and J. M. Mitchison, J. Cell. Sci. 112, 1085 (1999).

${ }^{31}$ J. B. Millar, G. Lenaers, and P. Russell, EMBO J. 11, 4933 (1992).

${ }^{32}$ A. Goldbeter and D. E. Koshland, Jr., Proc. Natl. Acad. Sci. U.S.A. 78, 6840 (1981)

${ }^{33}$ P. A. Fantes, in Cell Cycle Clocks, edited by L. N. J. Edmunds (Marcel Dekker, New York, 1984), p. 233.

${ }^{34} \mathrm{P}$. Nurse and P. Thuriaux, Genetics 96, 627 (1980).

${ }^{35}$ P. Fantes, Nature (London) 279, 428 (1979).

${ }^{36}$ J. J. Tyson, Proc. Natl. Acad. Sci. U.S.A. 88, 7328 (1991); B. Novak and J. J. Tyson, J. Theor. Biol. 165, 101 (1993); 173, 283 (1995).

${ }^{37}$ B. Novak and J. J. Tyson, Proc. Natl. Acad. Sci. U.S.A. 94, 9147 (1997).

${ }^{38}$ B. Novak, A. Csikasz-Nagy, B. Gyorffy, K. Chen, and J. J. Tyson, Biophys. Chem. 72, 185 (1998).

${ }^{39}$ A. Sveiczer, A. Csikasz-Nagy, B. Gyorffy, J. J. Tyson, and B. Novak, Proc. Natl. Acad. Sci. U.S.A. 97, 7865 (2000). 